\title{
DILEMAS DE LA INTERVENCIÓN DEL ESTADO EN LOS TERRITORIOS DE CHUMBIVILCAS. EL CASO DE VELILLE CON CHAMACA Y LIVITACA (CUSCO - PERÚ)
}

\author{
VELILLE CHAMACA LIVITACA CHUMBIVILCAS LLAQTAKUNAPI \\ ESTADO NISQA LLANK'AYNINWAN HAYKUYNIN (QOSQO- PERU \\ SUYUPI)
}

\section{DILEMMAS OF THE INTERVENTION OF THE STATE IN THE TERRITORIES OF CHUMBIVILCAS. THE CASE OF VELILLE WITH CHAMACA AND LIVITACA (CUSCO - PERU)}

\section{Hamilton Parra Argandoña(1)}

Ch'uyanchakuy: Kay articuluqa khuskiyta munan imaynatas Estado nisqa riman, haykumun allpakunaman. Empresa colonial nisqa kawsayta kay allpakunapi pakira, ruwasqanchiskunatawan pakira Chamaca, Livitaca Velillepiwan. Kunanqa Instituto Nacional de Estadistica e Informatica nisqa mapas referencialeskunata ruwachan, chay ruwayqa karu hina kan chay llaqtakunamanta, chayqa chaqwaykunata churan chay llaqtarunakunawan, chaymanta empresa minerapis churachan chaqwkuykunata allpa ruwasqanmanta, qasqanmanta, chayqa tupasqa Kachan capitalimo qolqewan. Chay raykun llaqtarunakuna imaymanta ruwan: distritalizaciónniqata Comunidades Campesinasnisqa huñukuy, chaqwakuykuna, millay tupaykunawan, paykuna munaku allpanku payunaman kutimunanta, hitokuna churasankuawan. Chaykunaqa Estadoq rimasqanmi, chay hinaqa tapuy kanman maykama Estadonisqa chayanman, desarrollonisqanman chayananpaq? Iskay rimay kan, hukmi yuyanhina utaq imaynas chay podernisqa kukunman? Chay hinaqa, Estadoqa suyuta wakirichin, pakirichintaq capitalismo kuskawan.

Yuyaysapa simikuna: Ayllu Suyu K'anchay, Peru Suyu, Kallpa, Allpa Saq'ay.

(1) Antropólogo, Docente de la Facultad de Derecho y Ciencias Sociales, Departamento Académico de Antropología y Sociología de la Universidad Nacional de San Antonio Abad del Cusco UNSAAC. Miembro fundador del Instituto Intercultural de Estudios Sociales y Políticos - IDESPO y del Laboratorio de Derecho, Sociedad y Política de la UNSAAC. Preocupado por el proceso de despojo y administración de los territorios, los conflictos socio ambientales y la cuestión de la Descentralización. 
Resumen : El presente artículo pretende analizar las implicancias que tiene el Estado tanto como discurso ideológico y como aparato de intervención institucional en el territorio. La empresa colonial desestructuró el espacio territorial, posteriormente la reorganización espacial de las jurisdicciones políticas administrativas impuestas en la época republicana han ocasionado fracturas socioculturales y territoriales en Velille, Chamaca y Livitaca. Actualmente, el Instituto Nacional de Estadística e Informática ha elaborado mapas referenciales, los cuáles distan de la ubicación real de dichos distritos, lo cual ha generado disputas entre sus habitantes; y, por otra parte, el establecimiento de la empresa minera está originando controversias por el uso y posesión del territorio, pues, dichos procesos están ligados al mercado y al capital. Situación que ha conllevado a que los habitantes de estas poblaciones tomen diversas posturas frente a un despojo territorial, derivando en iniciativas de distritalización, anexión de Comunidades Campesinas y latentes conflictos, planteando la reapropiación de sus espacios mediante la demarcación territorial. Estos hechos son expresiones cosificadas que cuestionan el rol del Estado frente al desarrollo del territorio. Existe una doble manifestación estatal, tanto como idea y como materialidad de poder, la cual necesita ser dilucidada.

Palabras clave: Demarcación territorial, Estado, Dilemas, Poder, Intervención, Desestructuración territorial, Desterritorialización, Reapropiación, Despojo territorial.

Abstract: The present article intends to analyze the implications that the State has both as an ideological discourse and as an institutional intervention apparatus in the territory. The colonial enterprise deconstructed the territorial space, later the spatial reorganization of the political administrative jurisdictions imposed in the republican era have caused sociocultural and territorial fractures in Velille, Chamaca and Livitaca. Currently, the National Institute of Statistics and Informatics has developed reference maps, which are far from the real location of these districts, which has generated disputes among its inhabitants; and, on the other hand, the establishment of the mining company is causing controversy due to the use and possession of the territory, since these processes are linked to the market and capital. Situation that has led to the inhabitants of these populations take different positions against a territorial dispossession, leading to initiatives of distritalization, annexation of peasant communities and latent conflicts, proposing the reappropriation of their spaces through territorial demarcation. These facts are reified expressions that question the role of the State in the development of the territory. There is a double state manifestation, both as an idea and as a materiality of power, which needs to be elucidated.

Key words: Territorial demarcation, State, Dilemmas, Power, Intervention, Territorial Destructuration, Deterritorialization, Re-appropriation, Territorial dispossession. 


\section{Introducción}

Se entiende al territorio como una "realidad compleja y multidimensional, resultado de la interacción acumulada en el tiempo de una sociedad con un medio natural, el cual esa sociedad transforma progresivamente para su usufructo, a través de sus actividades principalmente económicas, y de las infraestructuras que dispone para ello. Ello se expresa en procesos de transformación y apropiación social del territorio que se acumulan históricamente, producen formas de organización social para asegurar el dominio del mismo y están en la base de la construcción de culturas e identidades territoriales" (PRODES: 2006).

Desde la época colonial, los territorios de Chumbivilcas fueron desestructurados con el fin de asegurar intereses de orden económico y político principalmente, a tal punto de desmembrar y cambiar las estructuras de los antiguos ayllus y poblaciones que posteriormente se convirtieron en reducciones, curatos, corregimientos e intendencias entre otros. Aquí, el factor religioso cumplió el rol de evangelización como un medio de control social y de inicio del proceso de despojo territorial en las antiguas poblaciones asentadas en estos espacios.

Posteriormente, en la época republicana se dictan leyes de creaciones provinciales y distritales, las cuáles se deslegitiman y distan de la realidad sociocultural de los pueblos, ya que por lo común [dichas leyes] buscaron apoyar intereses económicos y políticos propios del capital; lo cual fue una expresión de la materialidad del Estado al reestructurar la composición socio política del Perú.

En la actualidad existen acciones del Estado (propiamente del Instituto de Estadística e Informática - INEI), referido a emisiones de mapas cartográficos referenciales, los cuales no se ajustan a la realidad socio territorial de los distritos de Velille, Chamaca y Livitaca, ya que en su delimitación consideran poblaciones que no necesariamente pertenecen a una determinada jurisdicción, tal es el caso de Velille con Livitaca y Chamaca. Quizá hasta este punto, no serían muy resaltantes las disputas y procesos de reapropiación del territorio iniciados posteriormente por las poblaciones de estos territorios, sino hasta el inicio de las acciones y operaciones mineras de Hudbay Perú S.A.C en terrenos donde se asientan las poblaciones de Velille, Chamaca y Livitaca.

En los años ochenta, las empresas Mitsui Mining Corporation (Mitsui) y Minera Katanga exploraron los yacimientos Constancia y San José (el Proyecto Constancia) mediante la realización de 48 perforaciones por un total de 5430 . Posteriormente, en octubre del año 2003, Río Tinto celebró una alianza estratégica (join venture) con Mitsui, con una participación del 70\% y $30 \%$ respectivamente, iniciando la exploración en diciembre de ese mismo año y completando 24 perforaciones diamantinas que sumaron $7843,9 \mathrm{~m}$. En octubre del año 2007, Hudbay adquirió de Mitsui su participación del 30\% y en noviembre de ese mismo año, hizo efectiva la opción inicial que le habría otorgado Río Tinto para adquirir un $51 \%$ adicional de participación en el proyecto. Luego, en marzo del 2008, Hudbay ejerció la segunda opción otorgada por Río Tinto, adquiriendo el 19\% de participación 
restante y consolidando, de esta manera, el control absoluto sobre el $100 \%$ del Proyecto Constancia (EISA: 2010, 2). Según Hudbay Perú, en 2011, Hudbay adquirió Norsemont Mining Inc. Y su proyecto de pórfidos de cobre de Constancia, lo cual se ubica en el sur de Perú y es su propiedad 100\%. La producción comenzó como se esperaba en el cuarto trimestre del 2014 y alcanzó la producción comercial el 30 de abril de 2015.

Todas estas dinámicas suscitadas en esta parte de Chumbivilcas han ocasionado también cambios en la composición social, económica y territorial, tales son las divergencias en la interpretación sobre la ubicación de sus distritos y poblaciones, el traslado y cambio de sus actividades agrícolas y ganaderas, ya que con el inicio de las actividades mineras se realizaron convenios específicos con algunas comunidades para la prestación de algunos servicios que requería la empresa minera, así como algunas actividades estipuladas dentro del Estudio de Impacto Ambiental de la Empresa Minera.

También se perdió parte de los patrones culturales de identificación de límites territoriales, tal es el caso de la destrucción del cerro Sayhualoma (punto de identificación fronteriza entre Velille, Chamaca y Livitaca), hubo afluencia de migrantes y el constante transporte de los recursos minerales con el consiguiente impacto producido en las poblaciones adyacentes, debido a las actividades de explotación y transporte de los materiales, Pues, la población de los mencionados distritos han sentido y sostenido que si se están explotando recursos minerales dentro de sus territorios, debe de haber también una retribución hacia ellos por parte de quien realiza la explotación, tal como establece el mismo Estudio de Impacto Ambiental y Social - EISA de Hudbay y todos los protocolos sobres responsabilidad socio ambiental.

Entonces, este tipo de elementos han contribuido a la reapropiación del espacio territorial de las poblaciones y jurisdicciones asentadas en los espacios de influencia de la empresa minera, mediante un proceso técnicoy político denominado demarcación territorial. Lo cual también ha revivido la reestructuración territorial inacabada, todavía venida de la colonia y de la época republicana.

Los espacios de demarcación territorial (los cuáles también se encuentran en controversia) comprenden los límites territoriales entre los distritos de Velille, Chamaca y Livitaca, el cual corresponde a 100.7 kilómetros lineales, mientras que la extensión de 3.3 km2 es el área entre los distritos de Velille y Chamaca y 27.1 km lineales entre los distritos de Velille y Livitaca.

Para este caso, los argumentos sostenidos se fundamentan en datos que fueron trabajados a partir de fuentes primarias mediante trabajos de campo, insitu, georeferenciación trabajada con la población, la cual se cotejó con la información geográfica, cartográficay degeoreferenciación dellnstitutoGeográficoNacional-IGN (datos que son referenciales) ya que en varios puntos no se corresponden; mientras que la información secundaria corresponde a documentos, acuerdos, actas, mapas antiguos de comunidades campesinas, leyes de creación, propuestas anteriores de determinación territorial, los cuáles fueron obtenidos en las Municipalidades de los 
distritos de Velille, Livitaca, y Chamaca, así como en el Gobierno Regional Cusco, en archivos históricos de Cusco, del Congreso de la República y de la Presidencia del Consejo de Ministros - Vice Ministerio de Gobernanza Territorial (ex Dirección Nacional Técnica de Demarcación Territorial - DNTDT) entre otros.

Mapa de identificación de controversias territoriales entre Velille, Chamaca y Livitaca

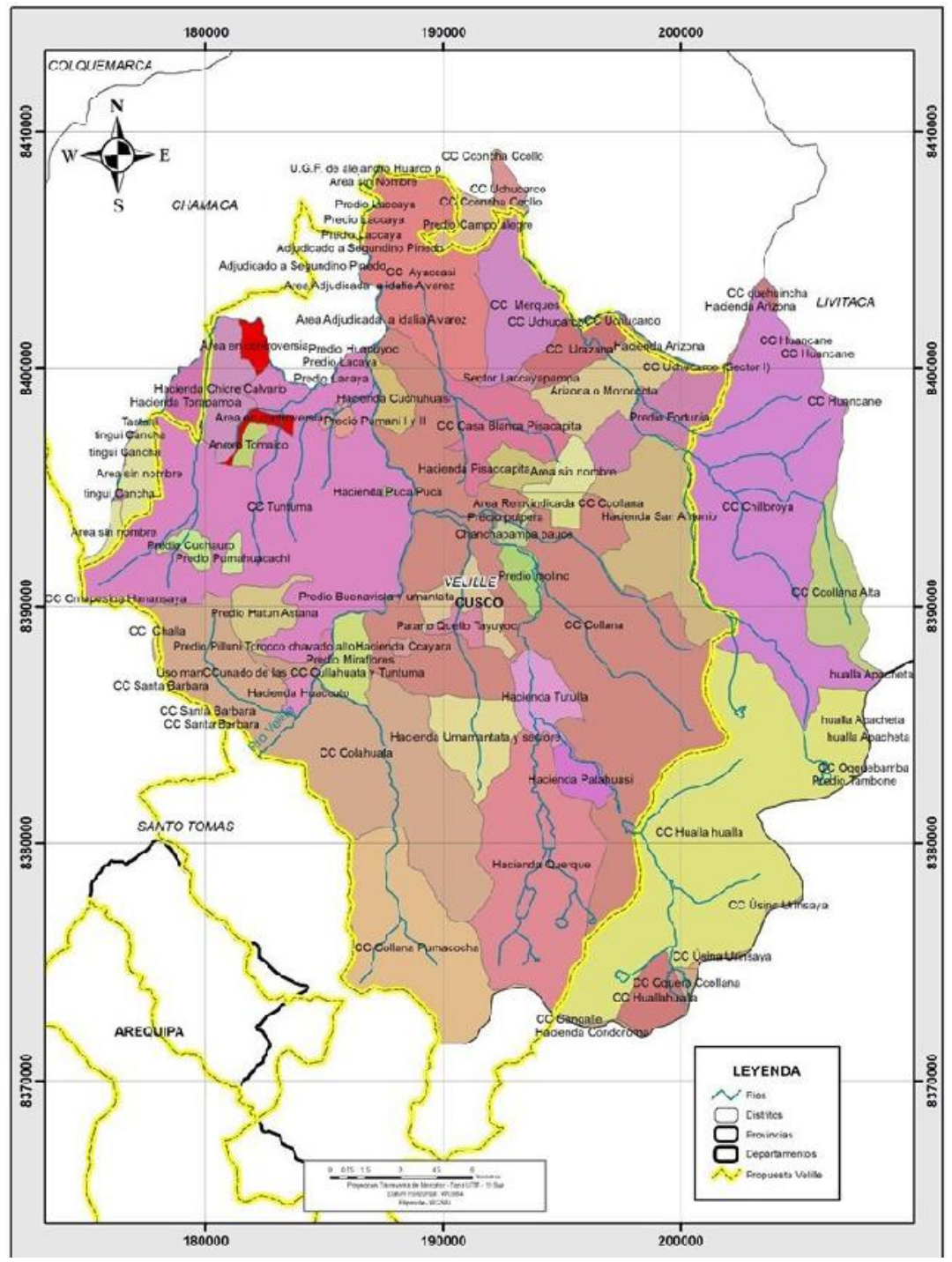

Fuente: Elaboración propia. 2016. 
En el mapa se puede observar que la elipse resalta la imprecisión de la ubicación jurisdiccional política y administrativa entre los distritos de Velille y Livitaca (EI INEI considera a Chilloroya, Urinsaya entre otros, como poblaciones que pertenecen a Velille, cuando no es así); y en la parte que resalta el círculo, también se observa la imprecisión de la demarcación entre Velille, Chamaca y Livitaca. La línea (propuesta de Velille) es la adecuada.

Según MITCHELL (2015) "el Estado es un objeto de análisis que parece existir simultáneamente como fuerza material y como constructo ideológico y ser tanto real como ilusorio". Pues, el Estado no se mueve ni se desarrolla aisladamente de la dinámica del sistema de acumulación de los espacios y del territorio, que es lo que en algún momento HARVEY denominó "acumulación por desposesión". Al respecto, HARVEY hace una mención importante a la acumulación por desposesión, considerando la dicotomía de que es el sistema en alianza con el Estado quienes se producen y reproducen a sí mismos en los espacios territoriales donde existen recursos naturales a ser explotados, los cuáles terminan beneficiando al capital. De esta manera, considera que "el ajuste espacio-temporal, por otra parte, es una metáfora de las soluciones a las crisis capitalistas a través del aplazamiento temporal y la expansión geográfica" (HARVEY, 2005). Es así que el proceso de acumulación por desposesión que produce el capital ${ }^{(2)}$ [proceso asociado al Capitalismo ${ }^{(3)}$, en este caso, a través de la Empresa Minera, estaría motivando la enajenación de los territorios de los distritos de Velille, Chamaca y Livitaca. Donde a través de los mecanismos del aparato estatal se obtuvo la concesión de territorios con vocación minera, en los cuales existen poblaciones que ancestralmente se han dedicado a actividades de agricultura, ganadería y minería entre otras actividades sociales y culturales dentro de sus espacios territoriales, actividades que los han conllevado a tener posturas diferentes respecto a la posesión y reapropiación del territorio en cuanto se han visto afectados en el uso y aprovechamiento del territorio por parte de agentes externos.

\section{La materialidad del Estado en el territorio}

La intervención del Estado por una parte se materializa en la "planificación" que este hace en su ámbito territorial, dentro del cual, una forma de establecer su poder sobre el territorio esa través de un mecanismo denominado Demarcación territorial, refiriéndose ésta a la determinación física y espacial de límites en el

(2) Capital: En Econ. Polít. El capital está constituido por los medios de producción, es decir, por los instrumentos fabricados por los hombres para poder trabajar más productivamente. La producción de bienes y servicios depende fundamentalmente de tres factores de producción imprescindibles: los recursos naturales (suelos, yacimientos, agua, aire, etc.), el trabajo y el capital. Enciclopedia Universal SALVAT. 2009. Pp. 2564.

(3) Capitalismo: Econ. Polít. Sistema económico basado en la propiedad de los medios de producción, que constituyen el capital. Normalmente el capitalismo está asociado a la libertad de mercado y a la libre iniciativa de las empresas en la determinación de sus productos y la fijación de los precios de éstos. Enciclopedia Universal SALVAT. 2009. Pp. 2568. 
territorio, situación que se ha generado en vista de los procesos de controversia territorial, producto de las divergencias en la interpretación y ubicación en espacios territoriales que no son cartografiables ${ }^{(4)}$ ni cartointerpretables ${ }^{(5)}$. Dentro de dicho proceso, se suscitan divergencias en la interpretación de ubicación de espacios territoriales como jurisdicciones distritales en ámbitos políticos - administrativos y Comunidades Campesinas, las cuáles han pasado por procesos de cambio social, territorial y político a lo largo de la época colonial, republicana y por la misma perturbación del capital, la cual está produciendo la desconfiguración del territorio.

Ante esta dinámica de cambios positivos y negativos suscitados en el territorio, los cuáles mantienen un carácter de tipo económico, social y político, surgen iniciativas y propuestas para la determinación, no solo de tipo física y espacial de límites del territorio, sino determinaciones reivindicativas de sus poblaciones involucradas, dentro de las cuáles, algunas de ellas estarían siendo promovidas por la empresa minera ${ }^{(6)}$, como es la distritalización de la Comunidad Campesina de Chilloroya (Livitaca). Al respecto, este tipo de cambios en el territorio, no solo son impulsados por la población, sino, más bien son impulsados y de manera estructural por las dinámicas del capital y del mercado, produciendo una desterritorialización social y cultural. Al respecto (HARVEY, 2005) menciona que "la expansión geográfica y la reorganización espacial son opciones posibles. Pero éstas tampoco pueden divorciarse de los ajustes temporales, ya que la expansión geográfica a menudo implica inversiones de largo plazo en infraestructuras físicas y sociales (por ejemplo, en redes de transporte y comunicaciones, educación e investigación).

Uno de los principales problemas asociados a las controversias territoriales y a la desposesión territorial son las imprecisiones de las circunscripciones políticas y administrativas que se originaron todavía desde la época colonial, continuada en la República y repetida de manera similar al patrón de "orden del territorio" en el proceso de construcción del Estado moderno. Los espacios territoriales de las etnias, ayllus y de las culturas que habitaban el territorio de Velille, Chamaca y Livitaca en la provincia de Chumbivilcas, se desestructuraron y desterritorializaron,

(4) y/o lugar.

(5) O sea, no contienen trazos que sean producto de la interpretación cartográfica de las leyes de creación o sus modificatorias

(6) Según el documento de Convenio Marco entre la Comunidad Campesina Chilloroya (Livitaca) y HUDBAY PERÚ S.A.C, de abril del 2012, en la parte NOVENA: COMITÉ MULTISECTORIAL PARA EL DESARROLLO, indica lo siguiente: “Corresponderá a esta comisión aprobar por consenso los proyectos a ejecutar en el marco de esta Programa de Desarrollo Sostenible Integral, previa evaluación de la pertinencia de su calidad e impacto positivo en la población de la COMUNIDAD. Los proyectos a ejecutarse preferentemente deberán estar en el marco del plan de desarrollo que establezca LA COMUNIDAD y bajo el asesoramiento de HUDBAY PERÚ, en el cual se promoverá, entre otros, la distritalización de LA COMUNIDAD. Los miembros del Comité Multisectorial para el Desarrollo se reunirán obligatoriamente de manera mensual y cada vez que así lo requiera cualquiera de las partes". 
ocasionando que también se vean impactadas negativamente las dinámicas de las relaciones económicas y culturales de las poblaciones que habitaban en dichos territorios.

En la actualidad, existe"una especie de ordenamiento irracional del territorio" el cual se limita a la existencia de circunscripciones por un lado pequeñas, y por otro lado extensas, asociado al bajo número poblacional, aspectos que limitan la actuación eficiente del Estado y el desarrollo territorial del Perú. Al respecto, es importante identificar y diferenciar cuál es la mirada y el patrón del concepto de desarrollo que el Estado ha tenido para con el territorio, para realizar modificaciones, trasladar poblaciones, realizando intervenciones como las concesiones sin tener en cuenta criterios mínimos acerca de los impactos y consecuencias que han sufrido las poblaciones asentadas.

Cabe hacer referencia al significado de Desarrollo que el Estado tenía en el año 1924, bajo el gobierno e Augusto B. Leguía con la Ley dada por el Congreso de la República, Ley $N^{\circ} 4891$, Sobre vagancia, por la cual definía al indio como vago, entendiendo que "Vago es todo individuo que, careciendo de bienes y rentas, no ejerce profesión, arte ni oficio; ni tiene empleo, destino, industria, ocupación lícita, ni otro medio legítimo ni conocido de subsistencia, o, fingiendo tenerlos, carece de casa habitación...". A través de dicha Ley se justificó el proceso de modernización del Perú, por ende, de desarrollo, que se dio en el gobierno de Leguía para construir carreteras que unieran al Perú, por el cual se dio ésta mencionada Ley de Conscripción Vial ${ }^{(7)}$. Vale cotejar el entendimiento de desarrollo que se tenía a principios del siglo XX con la concepción de desarrollo que ahora tiene el Estado; ¿quizá sólo se quede en algunas prácticas equivocadas y limitadas de la modernidad y del crecimiento económico, a costa de qué? ¿O de la pérdida espacial del territorio y del falso ordenamiento territorial estatal?

Al respecto ESCOBAR (2007) menciona que "la misma realidad ha sido colonizada en su totalidad por ese meta-discurso; tanto desarrollados como subdesarrollados". Pues, el discurso del desarrollo que transmite el Estado, de que solamente la inversión es el presente y futuro del Perú vía la concesión de territorios con vocación minera, como es el caso de las operaciones realizadas por la empresa minera en Velille (afectando también territorios de sus distritos colindantes de Chamaca y Livitaca), lo cual conlleva a entender una situación de causa y efecto. Esta es que, efectivamente, la población asentada en los territorios pobres de los andes del país se encuentra subdesarrollada, cuestión que lleva a plantear que se debe de generar su desarrollo a través de este tipo de inversiones las cuáles lítica vial agresiva. Por lo que una de las principales obras durante el periodo de Leguía fue la dación de la Ley de Conscripción Vial. El 06 de abril de 1920 se aprobó esta Ley entre los diputados, sin embargo, no toda la opinión pública estuvo de acuerdo. El 11 de mayo el gobierno aprobó la Ley de Conscripción Vial o del Servicio Obligatorio de Caminos. 
son poco planificadas; situándose en un escenario antagónico para justificar políticas de planificación y delimitación territorial que tiene que realizar el Estado, o sea llevar y generar la presencia del Estado en base a programas y proyectos de "desarrollo" plasmado en la construcción de postas, colegios, sistemas de riego entre otros, pero, que no serán posibles ser realizadas si es que no se genera una política de recepción y aceptación de la población a las inversiones mineras.

En cuanto a los problemas territoriales entre los distritos de Velille con Chamaca y Livitaca, éstos han sido provocados por varios factores, uno de ellos está referido a la desestructuración y desterritorialización producto de la colonia, otro a la inexactitud de límites territoriales producido en leyes republicanas de creación distrital y provincial y los errores e imprecisiones actuales del Estado a través del Instituto Nacional de Informática y Estadística - INE, el cual elaboró mapas poblacionales referenciales a nivel distrital y provincial, provocando para la posterioridad controversias y latentes conflictos en la determinación de las circunscripciones político - administrativas. En cuanto a las controversias por la posesión del territorio, ésta se origina en las delimitaciones y redelimitaciones que se operativizan en el territorio, dentro de la cual se encuentran las propuestas de determinación territorial en los distritos de Velille, Chamaca y Livitaca, a las que también se les puede denominar reconfiguración del espacio territorial, los cuáles no se encuentran ajenos a las dinámicas y presiones del capital y del mercado.

Del mismo modo, la anexión de circunscripciones y centros poblados, conteniendo las iniciativas en la reconfiguración del territorio; este último factor es expresado en las pretensiones de distritalización por parte de la Comunidad Campesina Chilloroya, distrito de Livitaca, la cual también no se encuentra ajena al aprovechamiento de los recursos económicos y como un proceso ligado al mercado, hecho que también estaría siendo motivado por la empresa minera que opera en dichos territorios ${ }^{(8)}$.

A continuación, se presenta las leyes de creación de la provincia de Chumbivilcas y de Velille (en la época republicana), donde se aprecia la descripción referencial, genérica e inexacta de su denominación.

(8) Según la Cartilla Informativa № 05, referida a Comunidades Campesinas y Minería: superposición de concesiones mineras en territorios comunales, de abril del 2018, elaborado por el Instituto del Bien Común - IBC y el Centro Peruano de Estudios Sociales - CEPES, el 26.5\% del territorio nacional está ocupado por Comunidades Campesinas, mientras que el $35 \%$ de las tierras de Comunidades Campesinas están concesionadas a las mineras, y el 14\% del territorio nacional tiene concesiones mineras. Es así que Cusco se encuentra entre los departamentos con mayor número de comunidades campesinas reconocidas, con un total de 930 comunidades, así también, el Cusco tiene la mayor extensión de áreas tituladas de Comunidades Campesinas, Ilegando a un área titulada total de 2,631,711 ha, constituyendo el $36.56 \%$ del territorio departamental. Dicha Cartilla considera que una de las mayores amenazas para los territorios comunales proviene de las actividades extractivas mineras por la enorme superposición de derechos mineros concesionados sobre sus territorios. Situación similar de la que no se encuentran exentos los territorios de Velille, Chamaca y Livitaca de la provincia de Chumbivilcas. 


\subsection{Creación de la provincia de Chumbivilcas y distrito de Velille}

Por decreto del 21 de junio de 1825 formalmente se constituye la provincia de Chumbivilcas, ello ocurre durante la primera elección popular que entonces se celebraban en las provincias y departamentos del País.

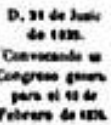

tore of to de

\section{EL. CONSEJO DE GOBIERNO:}

Por cuanto S. E. el Lasatraboat encargado del mando supremo de la República, en Grden comunicada desale Arequipa de 90 de Mayo anterior, ha tenido á bien, disponer que se reuna el Congreso general para el 10 de Febrero del próximo entrante año de $1826 \mathrm{a}$ fin de que se consagre desde luego, á discutir los altos intereses, y $\mathbf{A}$ dictar las leyes que hagan la felicidad de la nacion. Por tanto, en ejecucionde la expresada orden, para que las benéficas intenciones que en ella se manifiestan, tengan el mas pronto y cumplido efecto, segun las leyes y reglamentos que rigen, y para que los pueblos en el nombramiento de sus representantes gocen de la mas plena libertad, encontrando en el gobierno el mas firme apoyo, para el ejercicio de sus atribuciones soberanas.

Ha venido en decretar y decreta :

Art. 1. Se convoca el Congreso general del Perú para el dia 10 de Febrero del ah̃o proximo de 1826, en cuyo dia deberá instalarse en esta capital.

Art. 2. Se comunicará inmediatamente esta orden á los prefectos de los departamentos de la República, y estos la trans: mitirán á los intendentes de las provincias, acompañándoles ejemplares de la Constitucion y del reglameoto de elecciones.

Art. 3. Al recibo de esta orden se publicará sin pérdida de tiempo por bando en las capitales departamentales y de provincia, y se imprimirá en los papeles públicos para su mayor notoriedad.

Art. 4. Quince dias despues. de recibida y publicada como se previene en el antecedente articulo, se procederá á las primeras elecciones parroquiales, $y$ seguidamente á las que correspondan jara el nombramiento de diputados á Congreso, y diputados departamentales, con arreglo á la ley reglamentaria que trata del asunto.
Art. 5. Debiendo arreglarse el número

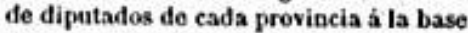
de 12,000 habitantes por cada uno; y no habiendo tiempo suffiente para formar los respectivos padrones, se regularán por el censo que se publicb en la guia del Perü ên el año de 1797, como el último que existe.

Art. 6. Conforme á este, se lormará y acompanarás lista del número de diputados que corresponde $\mathbf{a}$ cada provincia de las clases de propietarios y suplentes, y el total que debe nombrar cada departamento.

Art. 7. Las actas de elecciones se remitirán .por esta vez, en falta del Seuado conservador, al gobierno, cerradas y selladas por los colegios electorales.

Art. 8. Las provincias pro veeráncon Iamayor anticipacion las dietasá losdiputados propietarios con el fin de que se presenten en la capital para el mes de Diciembre del presente año, al respecto de diez pesos diarios, y doce reales por legua para el viaje.

Imprimase, publiquese y circulese, quedando encargado del cumplimiento

de este decreto el ministro de Estado en el departamento de Gobierno.

Dedp en el palocis del Soprens Gebierso et Lima

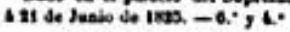

Hipseito Uraxuz. - Joar Sacazan.

Por orden de \$, R.

Toxds be fienes.

Lista de los señores diputados que corresponden d los diversos deportameitios, conforme at censo que se publies en las gutias del Peril para el aìo de 1797. 

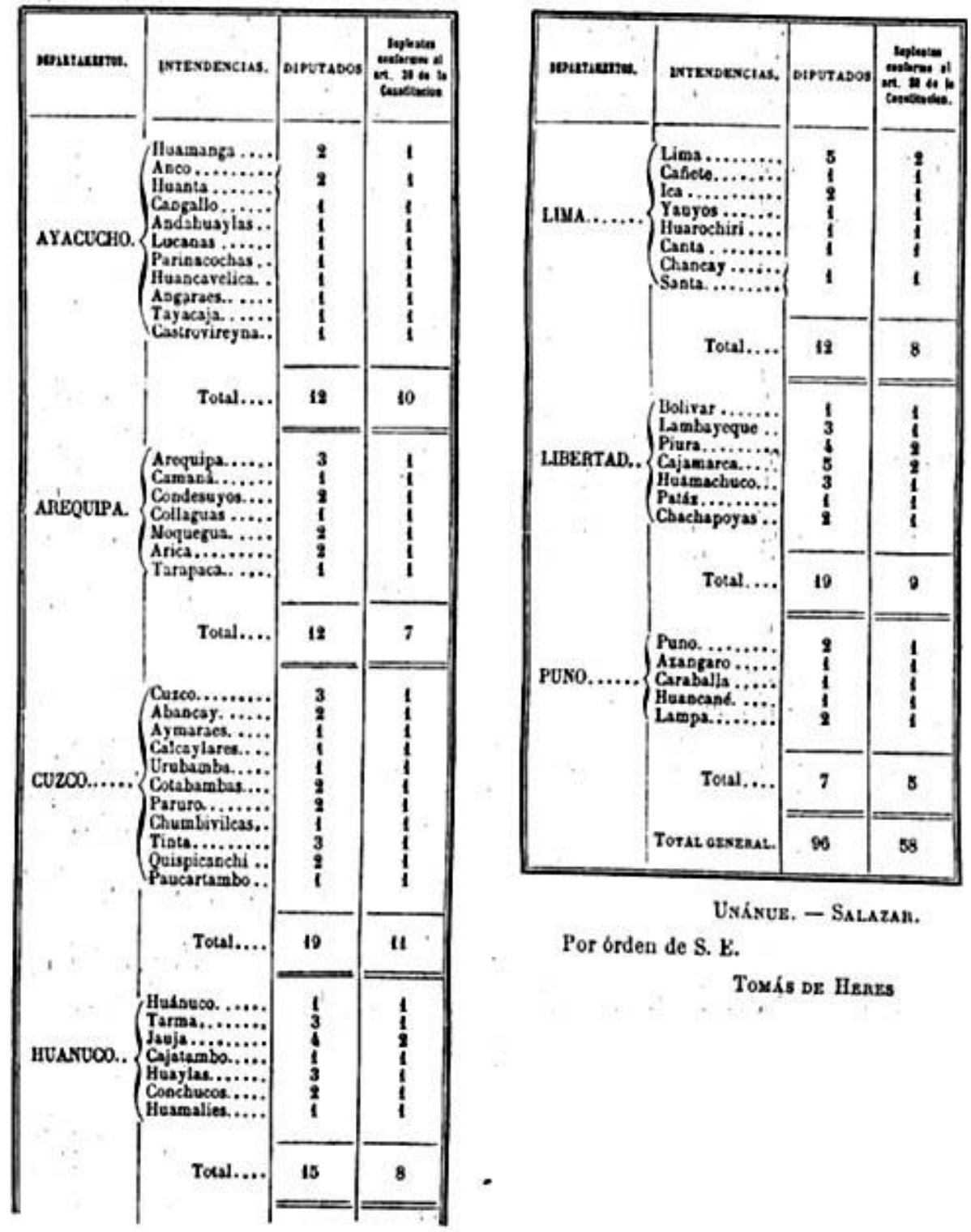

Por órden de S. E.

Touís de Hears 
2.2 Ley de creación política, pueblo de Velille, capital de Chumbivilcas 31 de diciembre 1839

El ciudadano Agustin Gamarra, gran mariseol de los ejercitos nacionales; Presidente provisorio de la liepública, etc.

Por cuanto el Congreso laa dado la ley siguiente :

\section{RL CONGRESO GENEIIAL}

DEL PEIIU.

\section{Considerando :}

Que la Nacion debe premiar los servicios prestados por los pueblos en la guerra de la independencia;

\section{Decreta :}

El pueblo de Santo Tomás será la capital de Ia provincia de Chumbivilcas denominándose Villa. Igual tilulo llevará cl pueblo de velille de la inisma provincia.

Comunicucse al Poder Ejecutivo para que disponga lo necesario á su cumplimicnto, mandándolo imprimir, publicar y circular.

llado en la sala de sesiones lul Congreso, en Hinan. cayo, a 98 de Noviembre de 1830.

Lucas Pellicer, presidente. - Jenvasio Al. varez, Diputado secrolario. - AGUSTIN Gaziano. Diputado secretario.

Por tasto, massdo se imprima, publique y circule, y se le dé cl debido cumplimiento.

Dado en la casa del Supremo Gohierno, en Lima, $s$ .1 de Diciembre de 1834.

$$
\text { - Aristin Ganania.- }
$$

Por órden de S. E. - Manuez Fgnnetnos 
Al respecto (PEIGNE, 1994) sostiene que "la conquista española introdujo una nueva racionalidad en el manejo espacial, que ocasionó la crisis territorial moderna, desde entonces la dialéctica territorial ocasionó desmembramiento de los territorios étnicos, y dio origen a los procesos de ordenamiento territorial". Al respecto, amerita afirmar que, efectivamente, este proceso de implementación de programas de desarrollo y crecimiento en el territorio, desde una perspectiva neocolonial, no ha variado en el fondo, a comparación de la imposición de modelos tradicionales de "desarrollo" ajenos a la realidad socio espacial de las poblaciones alto andinas con mayor componente originario de su población. En la actualidad, la mayor parte de las circunscripciones políticas - administrativas del Perú y en Chumbivilcas son reflejo y consecuencia de la formación de las reducciones, curatos, intendencias, corregimientos y formas de organización territorial venidas desde la colonia y la república. Siendo uno de los dilemas de la intervención del Estado en el territorio.

Con respecto a la composición de las divisiones territoriales (BUENO, 1951) afirma que "dentro de las divisiones territoriales implantadas por la colonia, encontramos un orden político (corregimientos) y la otra división eclesiástica, arzobispados, estas no tenían coincidencia y trascendían hasta otras jurisdicciones, produciéndose sobreposición de funciones administrativas en la colonia". Pues, en lo referente a la provincia de Chumbivilcas, la actual capital provincial, Santo Tomás y el distrito de Velille en la colonia y en la época republicana fueron centros jerárquicos importantes dentro de las dinámicas socio económicas, inclusive el distrito de Velille fue elevado a la categoría de capital de Chumbivilcas. No es casual que en la actualidad se pueda apreciar algunas construcciones y símbolos del poder eclesiástico en Velille, como su templo colonial que se encuentra en la capital distrital y otro también de factura colonial ubicado en la Comunidad Campesina de Ayahasi. Ahora, el poder eclesiástico ya no ejerce ni tiene el poder absoluto (junto al político) de años atrás, pero las consecuencias de la producción del espacio expresado en las actuales circunscripciones políticas y administrativas de los distritos es vigente.

No obstante, en el actual contexto social y político del Perú, el Gobierno Central apertura de manera desmedida las inversiones para la extracción de recursos minerales e hidrocarburíferos al capital extranjero ${ }^{(9)}$, producto del cual

(9) Considero y sostengo que las poblaciones de estos territorios no están en desacuerdo ni en contra de dar apertura y promoción a las inversiones económicas. Sin embargo, la forma y manera en que el Estado posibilita las inversiones para la explotación minera e hidrocarburos no son los más adecuados ni recomendables, porque no son sostenibles, así como por las perturbaciones e impactos negativos que originan en el territorio, por el poco o nulo diálogo con las poblaciones que son dueños de dichos territorios así como por el poco respeto y desconocimiento que muchos entes del Estado tienen respecto a la realidad pluriétnica, sociocultural y sobre la diversidad geográfica del Perú. Muchas veces, algunas empresas mineras, recurrentemente se aprovechan de este contexto y de estos vacíos que existen, responsabilizando de dichos problemas al Estado, sin tener en cuenta que ellos también deben de cumplir su rol de responsabilidad socio ambiental estipulado en una variedad de normativas internacionales. 
se agudizan los planteamientos y reapropiación del espacio territorial sostenido en demandas de demarcación territorial e iniciativas de reconfiguración territorial, plasmadas en iniciativas de distritalización, anexiones de circunscripciones político administrativas entre otros. Por lo cual, es necesario volver a diagnosticar y replantear el modelo de desarrollo, si es que se le puede hablar de un modelo de desarrollo territorial todavía inexistente en el país.

Este tipo de hechos llevan a poner en tela de juicio y a cuestionar que el escenario propuesto para el impulso del desarrollo en el Perú no es en realidad el tipo de calidad de vida que necesariamente espera y necesita la ciudadanía, mucho más aún las comunidades campesinas de Chumbivilcas. Al contrario, este planteamiento del desarrollo lleva a sostener que existen factores de tipo legal, político y económico por parte de la maquinaria estatal en complicidad del capital para generar controversias dentro de sus territorios, promover procesos de distritalización y realizar convenios específicos para el beneficio de intereses privados, algunos nacionales, así como para algunos pobladores y dirigentes de las comunidades; lo que estaría llevando a que las autoridades y población de Velille, Chamaca y Livitaca replanteen la reapropiación de su territorio ante la incursión del Estado y de la empresa minera en pro de la desestructuración del territorio. Dicha reapropiación del territorio se está plasmando en sus propuestas de redelimitación territorial presentada ante el mismo Estado [porque el marco legal así lo exige], el cual ocasiona una serie de posturas y divergencias.

Es así que en el contexto socio político del Perú, las contradicciones que el Estado ocasiona a partir de su accionar en el territorio, están generando conflictos por límites territoriales, tal es el caso del distrito de Quellouno, perteneciente a la provincia de La Convención, con el distrito de Yanatile (provincia de Calca); por lo cual, la Dirección Nacional Técnica de Demarcación Territorial - DNTDT (ahora suscrita al Viceministerio de Gobernanza Territorial), en un informe de inicios del año 2015 se concluye que: "El origen de la controversia, se puede encontrar en la imprecisión de las leyes de creación de los distritos y/o superposición de territorios, que en el marco de las competencias transferidas el Gobierno Regional del Cusco, no han podido ser atendidas ni resueltas....Sin embargo, es importante hacer notar que, el problema de fondo es la aspiración de recibir mayor asignación presupuestal del canon gasífero, como recurso extraordinario, por la Municipalidad de Yanatile, y que es la que menos recibe, de la distribución del canon".

Por otra parte, el 26 de enero del año 2016, el Poder Ejecutivo, con la firma del ex presidente Ollanta Humala y Premier Pedro Cateriano, emiten el Decreto Supremo N ${ }^{\circ}$ 008-2016-PCM, declarando como zona de interés nacional a la provincia de Cotabambas del departamento de Apurímac, para la ejecución de acciones de demarcación territorial, en dichos territorios se encuentra el proyecto minero de "Las Bambas". Comparativamente, dentro de las controversias territoriales entre los distritos de Quellouno y Yanatile, pertenecientes a las 
provincias de La Convención y Calca respectivamente, así como la declaratoria de interés de la provincia de Cotabambas, se advierte que en el primer caso existe un potencial de recursos hidrocarburíferos, mientras que en el segundo caso se encuentran recursos mineros; pues, no es casual que la existencia de controversias territoriales se intensifiquen en la medida que también el capital y el crecimiento económico se hacen más visibles en las poblaciones de estos territorios.

Tampoco es casual observar un similar problema de tipo territorial donde existe explotación de minerales, tal es el caso de que los espacios territoriales de los distritos de Velille, Chamaca y Livitaca, se vean impactados por un proceso de controversia territorial y cuasi conflicto social. Es de notar que existe la demanda de varios sectores sociales por beneficiarse del canon minero, así como de los proyectos e incentivos económicos y de convenios existentes con la Empresa Minera, lo cual es natural y legítimo. Estas dinámicas, económicas, sociales y políticas sobre el territorio llevan a sostener que no necesariamente el Estado está ejerciendo gobernabilidad sobre el territorio. Sino, y más al contrario, encontrándonos dentro de un Estado y de un territorio "indivisible y soberano", también pueden existir micro poderes supranacionales que estén perturbando los roles y funciones que el Estado debería de asumir para ordenar el territorio, acorde a las realidades geográficas y pluriétnicas dado el caso.

En Chumbivilcas, no necesariamente se estaría generando un equilibrio del desarrollo territorial, tal como las Naciones Unidas recomiendan con el desarrollo territorial por cuencas o como la misma Empresa Minera y el Estado se proponen [sólo en los papeles], pues, todo queda en "buenas intenciones". Sin embargo, "es importante trabajar en la posibilidad y concreción, no casual ni accidental, sino planificada y políticamente responsable, los problemas territoriales existentes en esta importante provincia del Cusco, no para expandir el ejercicio burocrático del Estado" (FERGUNSON, 2012) sino para construir alternativas y propuestas antagónicas a la desestructuración y desconfiguración territorial que pone en jaque el capital, utilizando como instrumento al Estado. Es así que, dentro del proceso de desestructuración territorial, nace el intento por reconfigurar el territorio, por lo cual el distrito de Velille junto a los distritos de Chamaca y Livitaca presentan propuestas de delimitación y redelimitación del territorio, lo cual se sustenta en un proceso de reapropiación y de defensa de sus territorios.

\section{Aproximación a algunas conclusiones}

1. Los espacios territoriales, así como las circunscripciones políticas administrativas, en el Perú y en la provincia de Chumbivilcas son el reflejo y consecuencia de la formación de las reducciones, intendencias, corregimientos, curatos y formas de organización territorial producidas desde la Colonia, desde la República y continuadas en el proceso de modernización del Estado, lo cual no necesariamente beneficia al proceso de la reorganización territorial, convirtiéndose 
en una suerte de caja de pandora que perturba el desarrollo de las poblaciones asentadas en dichos espacios.

2. Es el Estado quien reestructura el espacio territorial. Esta idea lleva a plantear un dilema desde su actuar, en el que al mismo tiempo promueve la "organización", "la planificación" y demarcación del territorio a la vez que emite mapas genéricos e imprecisos del territorio, ocasionando disputas y controversias en la población asentada en dichos espacios. Pues, ésta afirmación conduce a corroborar que, la construcción material a través de sus instituciones e instrumentos de poder y la idea que se tiene de él desde la reapropiación de los espacios territoriales es un hecho real y objetivo ya que está originando procesos de reterritorialización en perjuicio de sus habitantes.

3. En el actual contexto social y político del Perú, el Gobierno Central apertura de manera desmedida las inversiones para la extracción de recursos minerales e hidrocarburíferos al capital extranjero, producto del cual se agudizan e incentivan los planteamientos y reapropiación del espacio territorial expresado en las demandas de demarcación territorial y las iniciativas de reconfiguración territorial, de distritalización, de anexiones de circunscripciones político administrativas. Por ende, es necesario volver a diagnosticar y replantear el modelo de desarrollo, si es que se le puede hablar de un modelo de desarrollo territorial todavía inexistente en el país.

4. Los problemas territoriales en la provincia de Chumbivilcas, distritos de Velille, Chamaca y Livitaca son hechos sociales que ponen en tela de juicio el mismo modelo de Desarrollo y el modelo económico de mercado, donde el escenario propuesto para dicho impulso desde el Estado no es en realidad el tipo de calidad de vida que necesariamente espera y necesita la ciudadanía, mucho más aún las comunidades campesinas de Chumbivilcas. Pues, este planteamiento del desarrollo lleva a sostener que existen factores de tipo legal, político y económico por parte de la maquinaria estatal en complicidad del capital para generar controversias dentro de sus territorios, promover procesos de distritalización y realizar convenios específicos para el beneficio de intereses privados, algunos nacionales, así como para algunos pobladores y dirigentes de las comunidades; lo que estaría llevando a que las autoridades y población de Velille, Chamaca y Livitaca estén replanteando la reapropiación de su territorio ante la incursión del Estado y de la empresa minera en pro de la desestructuración del territorio. Dicha reapropiación del territorio se está plasmando en su propuesta de redelimitación territorial.

5. Las dinámicas económicas, sociales y políticas sobre el territorio llevan a sostener que no necesariamente el Estado está ejerciendo gobernabilidad sobre éste. Sino, encontrándonos dentro de un Estado y de un territorio "indivisible y soberano", también pueden existir micro poderes supranacionales que estén perturbando los roles y funciones que el Estado debería de asumir para no sólo ordenar el territorio, sino para defender sus recursos y a la población. 
6. "Es importante trabajar en la posibilidad planificada, política y socialmente responsable de los problemas territoriales existentes en Chumbivilcas, no para expandir el ejercicio burocrático del Estado" (FERGUNSON, 2012) sino para construir alternativas y propuestas ${ }^{(\mathbf{1 0})}$ antagónicas a la desestructuración y desconfiguración territorial que nos pone en jaque el capital, utilizando como instrumento al Estado.

\section{Bibliografía}

BUENO, C. (1951). Geografía del Perú Virreynal. Siglo XVIII. Buenos Aires. Argentina: Editorial Don Bosco.

CONGRESO DE LA REPÚBLICA PERÚ. (2002). Ley de Demarcación y Organización Territorial. Lima: Editora Perú.

CONVENIO MARCO DE DESARROLLO SOCIAL INTEGRAL (2012) Convenio entre la Comunidad Campesina de Chilloroya (Livitaca) y Hudbay Perú S.A.C del 12 de abril

DIRECCIÓN NACIONAL TÉCNICA DE DEMARCACIÓN TERRITORIAL. Territorial, D. N. (2013). Plan Nacional de Demarcación y Organización Territorial. (2013). Lima - Perú. Dirección Nacional Técnica de Demarcación Territorial - DNTDT (ahora Viceministerio de Gobernanza Territorial) Lima.

ESCOBAR, A. (2007). La invención del Tercer Mundo. Construcción y deconstrucción del desarrollo. Caracas, Venezuela: Fundación Editorial el perro y la rana.

FERGUNSON, J. (2012). "La maquinaria antipolítica. Desarrollo, despolitización y poder burocrático en Lesoto". En Beatriz Pérez (Ed.) Antropología y desarrollo: Discurso, prácticas y actores. Madrid - España.

(10) La experiencia del pueblo kandozi es interesante. Ellos habitan las cuencas de los ríos Chapuri, Morona y Pastaza, en las provincias Datem del Marañón, Alto Amazonas y Loreto, en el departamento de Loreto. Una de las características fundamentales de los Kandozi es que su residencia constituye un punto central en la percepción de su espacio. Pues, se reconoce que gracias a la acción de las organizaciones indígenas los territorios de los Kandozi han sido demarcados, reconocidos y titulados por el Ministerio de Agricultura-MINAGRI. Hacia inicios de diciembre del año 2016 se constituyó el Gobierno Autónomo del Pueblo Kandozi en la Comunidad Nativa de Musa Karusha. Este pueblo, junto con otras poblaciones vecinas, se dedicaron a recomponer su territorio ancestral de la autodemarcación de su posesión territorial. Pues, a través de su gobierno interno, se empieza a ejercitar su derecho a la libre determinación, lo cual significa que el pueblo tiene derecho a decidir la forma cómo se propone desarrollarse y bajo qué reglas administrará su territorio. Dichos territorios han sido declarados en diversos momentos como reserva forestal por el MINAGRI, zona reservada por el Ministerio de Pesca, Sitio Ramsar, como humedal de importancia mundial por la UNESCO entre otros. 
HARVEY, D. (2005). El "nuevo" imperialismo: Acumulación por desposesión. Buenos Aires. Argentina: Consejo Latinoamericano de Ciencias Sociales - CLACSO.

INSTITUTO DEL BIEN COMÚN - IBC (2018) "Comunidades Campesinas y Minería": Superposición de concesiones mineras en territorios comunales. Lima, abril del 2018

INSTITUTO GEOGRÁFICO NACIONAL - ING. Ministerio de Defensa - Perú.

KNIGHT PIÉSOLD CONSULTING. Hudbay Perú S.A.C (2010) Proyecto Constancia. "Estudio de Impacto Social y Ambiental) Resumen Ejecutivo. Santiago de Surco, Lima 33, Perú.

MITCHELL, T. (2015). "Sociedad, economía y el efecto del Estado". En Antropología del Estado. Ciudad de México: Fondo de Cultura Económica.

PEIGNE, A. (1994). Territorialidad andina. Aproximación a la gestión del espacio intercomunal. La Paz. Bolivia: Facultad Latinoamericana de Ciencias Sociales FLACSO.

PROGRAMA PRO DESCENTRALIZACIÓN - PRODES. USAID.

Enciclopedia Universal SALVAT (2009). Enciclopedia Universal, Volumen 6. Editorial SALVAT. Madrid - España.

VICEMINISTERIO DE GOBERNANZA TERRITORIAL - PERÚ. Ex Dirección Nacional Técnica de Demarcación Territorial - DNTDT. Presidencia del Consejo de MinistrosPCM. 